\title{
Social Networking Sites in the Aftermath of a Crisis-The Enabling Role for Self-Organization
}

\author{
Diana Fischer \\ University of Bamberg \\ diana.fischer@uni-bamberg.de
}

\begin{abstract}
During crisis circumstances, people increasingly rely on social networking sites (SNS). SNS offer new ways for people to participate and communicate, including seeking local and timely information and activating their social networks quickly, which in turn supports self-organization during crisis events. However, little is known about the motives that influence people's different SNS usage behavior for the goal of selforganization and the underlying mechanisms of this behavior. Based on uses and gratifications theory and the literature on crisis communication and crisis informatics, this conceptual paper argues that during crisis circumstances, particular needs influence people's SNS usage for the goal of self-organization. In addition, the paper investigates the conceptual underpinnings of self-organization via SNS. This paper, therefore, contributes to theory by developing a conceptual model for the analysis of self-organization via SNS during crisis circumstances.
\end{abstract}

\section{Introduction}

With the emergence of new information and communication technologies (ICT), particularly social media, people can access information about the world in ways and at speeds never before possible [73]. Social networking sites (SNS), for example, enable people to upload, share, and consume information from their smartphones or other internet-enabled devices to a large group of users in real time [65]. This makes SNS an ideal means to disseminate information and breaking news directly from a geographical point of interest or directly from the news source (e.g., [48, 52, 54]).

Given the growing ubiquity, accessibility, and efficiency of information exchange, SNS are playing an increasingly critical role in response actions following crises, such as earthquakes, flooding, and terrorist attacks (e.g., [10, 14, 32, 87]). SNS empower people at the scene of a crisis - equipped with digital devices - to provide breaking news about the events in a timely manner [30]. Local eyewitness often report on the crisis, and this information is rapidly distributed through SNS to inform others [50,51].

In addition, people use SNS not only for actively providing information but also for seeking and sharing crisis-related content. In particular, in highly dynamic and uncertain crisis situations, people have a high demand for information because they want to reduce uncertainty about the situation. Thus, members of the public use SNS to seek, share, and comment on crisisrelated information-especially when other information sources do not provide relevant news in a timely manner (e.g., [28, 32, 51, 52, 73]).

Furthermore, people affected by a crisis often serve as (first) responders, helping themselves and others by leveraging their local knowledge [51, 53, 84]. Indeed, research has shown that such emergent organizations (i.e., groups of people that had no structure or defined tasks before the crisis) use SNS during crisis circumstances to organize themselves [72]. Leong et al. [40], for instance, found that people used SNS to coordinate their activities, such as delivering food to people in need, collecting resources, and providing transportation, during the Thailand flooding in 2011. Similarly, following the 2010 Haiti earthquake, SNS were used to coordinate emergency response efforts between the many people affected [87]. SNS allow people across geographical boundaries to connect with others effectively, make decisions based on the information provided, and coordinate crisis relief efforts.

Although the topics of self-organization via SNS $[40,72]$ and different participatory behavior in SNS during crises $[80,81]$ are gaining increased attention in the academic literature, a conceptual model explaining the underlying relationships is missing [19]. This paper attempts to fill this gap by 1) investigating the conceptual underpinnings of self-organization via SNS along with its antecedents, 2) using the theoretical lens of uses and gratifications theory (U\&G) to examine the role of SNS for self-organization during crisis events, and 3) providing propositions and guidance for future research. To develop the conceptual model, this paper employs $U \& G$ as the overarching research framework. 
U\&G links different needs that emerge during crisis circumstances (e.g., reducing risk and uncertainty, exchanging trustworthy information, establishing a sense of community) with people's use of SNS to seek, share, and comment on information with the goal of self-organization in the aftermath of a crisis.

On the one hand, this paper seeks to contribute to the understanding of the factors causing crisis-related SNS usage for the goal of self-organization. On the other hand, it conceptualizes self-organization via SNS in the aftermath of a crisis. This paper, therefore, contributes to theory as it aims to provide insights regarding people's SNS usage behavior for selforganization during crisis events, and it develops a conceptual model as a basis for future research.

The paper proceeds as follows: Section 2 presents the theoretical background on U\&G, crisis events, SNS, people's SNS usage behavior, and selforganization. Section 3 describes the conceptual model and the propositions based on the theoretical insights. Section 4 provides the discussion, limitations and recommendations for future research. Finally, the contributions for theory and practice are identified, and a conclusion is presented.

\section{Theoretical background}

\subsection{Uses and gratifications}

To explore the factors driving SNS usage, U\&G serves as the overarching framework of this paper. U\&G postulates that people are aware of their needs, evaluate different communication channels and content, and then choose a medium they believe will gratify those needs [33]. U\&G has been applied widely in studies exploring the motives, behaviors, and satisfaction of users of various types of traditional media, such as television, radio, and print media [61]. In recent years, research has expanded the $U \& G$ framework beyond traditional mass media to account for the use of hybrid and interpersonal channels, such as the internet, mobile phones, and SNS (e.g., [11, 29, 82]). These channels enable higher degrees of audience selection and content control that stress users' ability to select and use media actively to satisfy their specific needs [12].

According to Blumler [6], the basic assumption of $U \& G$ is that individuals' use of media and its effects on them are influenced by several factors working together. These factors are derived from one's environment, psychological circumstances, motives, needs, and expectations about the communication [33]. Thus, instead of providing a predefined set of factors, U\&G considers relevant social and psychosocial antecedents and the consequences associated with media usage, which are in turn closely related to the nature of the communication medium.

$U \& G$ is particularly suitable for investigating the factors underlying SNS usage during crisis circumstances because it incorporates a variety of usage behavior as well as environmental and social conditions, all of which influence user needs. During crisis events, special needs may arise that people actively try to meet through SNS use $[18,76]$. Following these assumptions, this paper argues that people facing a crisis may have particular needs that they try to actively gratify by using SNS.

\subsection{Crisis}

A crisis is a specific and surprising event that creates the perception of a severe threat and high uncertainty [63]. More specifically, it is as an event observable in time and space during which society, communities, and/or regions suffer physical harm and loss of or disruption to their normal functioning [35]. High-magnitude crises often have not only immediate but also long-term catastrophic consequences for the affected community as evidenced by crises like the 9/11 terrorist attacks or Hurricane Katrina in the United States [4]. By definition, crisis events are outside established patterns, routines, norms, expectations, and belief systems. Although all crises are unique at some level, there are common features that are typically present in terms of cause, location of the threat, and consequences [63].

Because crises are low-probability, high-impact events, they impose severe demands on sense-making [83]. Following a crisis-triggering event, people are confronted with uncertainty due to the sudden highdynamic and unexpected situation, high risk, time pressure, damage, and infrastructure disruption [13]. Immediate communication between the people involved can reduce this uncertainty about the cause, consequence, and level of harm to create an understanding of what happened and what people can do to protect themselves [41]. Moreover, in crisis situations, especially when the consequences are seen as direct or personal, people are likely to perceive a risk, which is defined as "the chance of a loss" ([69], p. 220). In turn, risk perception has a confirmed impact on human behavior [4]. Both factors-namely, high uncertainty and risk - are key characteristics of a crisis and affect people's needs and communication behavior (e.g., $[41,62,64])$.

In addition to these two factors, trustworthy information exchange has been widely noted in the prior literature as a key factor influencing people's communication behavior with respect to crisis-related information (e.g., [24, 45, 59, 66, 74]). During a highly 
dynamic and uncertain crisis situation, people have an increased need for trustworthy information exchange because they have to make important decisions and take action based on the information provided [56].

Furthermore, in the aftermath of crisis events, people show an increase in altruistic behavior, such as the need to rebuild the community and help others affected by the event $[58,67,76]$. This mutual caring and aid to others represents an outward need of community concern during crisis events [67]. Consequently, in addition to uncertainty and risk reduction, this paper incorporates trustworthy information exchange and the need to rebuild and establish a sense of community as motivators affecting people's SNS usage during crisis circumstances.

\subsection{Social networking sites}

SNS enable users to construct unique profiles hosted on their platforms, establish a list of users with whom they share a connection, view and traverse their own list of connections, and view connections made by others within the SNS platform [7]. Additionally, SNS provide several tools for two-way communication and many-to-many information broadcasting in real time, such as chatting, uploading content, sharing information, browsing others' published information, posting, and leaving public comments $[21,86]$. These features enable users to share news and reach people all over the world without the intervening activity of journalists or other parties (e.g., [38, 42, 78]).

During crisis situations, people increasingly rely on peer-distributed content, often finding it to be more precise and timely than official news sources. In contrast to the latter, SNS content can provide a more local context and faster updates for people who need to make decisions about their actions [54]. In particular, SNS offer new ways for people to participate during crisis events, including seeking local and timely information, quickly activating their social networks, and making these efforts more visible. These features enable a new form of citizen journalism and active public participation during various crisis events [38], such as earthquakes (e.g., [43, 70, 88]), floods (e.g., [5, $77,79]$ ), terrorist attacks (e.g., [10, 14, 51]), hurricanes (e.g., $[20,44,58]$ ), and campus shootings (e.g., [27, 46, 79]). Different SNS are used in crisis-related communication, such as popular SNS like Facebook and Twitter but also more specific crisis-related platforms like Ushahidi [72]. This paper focuses on the former platforms because those SNS were frequently mentioned in the literature this paper is based on.

The literature has identified that the public participates in SNS during crisis circumstances to stay informed (e.g., $[8,46,54])$ and to exchange information (e.g., [40, 72, 81]). These actions can be categorized into three distinctive participatory behaviors [80]. First, users seek information, which is defined as browsing crisis-related and other relevant information and content in SNS. Second, users comment on crisis-related content, which includes posting responses to content, liking content, linking to other content, and sharing content from others in SNS. Third, users share new information, such as uploading photos or posting new crisis-related information in SNS [80, 81]. According to Wang [80], these participation behaviors in SNS require different levels of cognitive effort. Seeking information, for example, is quite easy because it requires relatively less effort. Furthermore, while commenting involves only slightly more effort than seeking, sharing new content requires much more engagement because people need to have new information and organize that information in a meaningful way. If an activity requires too much effort, people are less likely to participate in it [80]. Therefore, in line with the findings of Wang [80,81], this paper includes three participatory behaviors, namely information seeking, information sharing, and commenting in SNS.

\subsection{Self-organization during crisis}

Self-organization regarding crisis relief effortsalso referred to as grassroots participation [52] - has been observed in different communities after different crisis events (e.g., [26, 39, 52, 52, 70, 72]). Earthquakes, hurricanes, tidal waves, and terrorist attacks often mobilize many people who want to help and rebuild their community [60]. Such situations generate altruistic motivations based on emotional solidarity and the mutual need to help each other [85]. Affected people have been found to be the true "first responders" and also often continue their efforts when professionals arrive at the crisis area [52]. Thus, instead of staying inactive, many people - at least to the extent they can - respond to crises by offering help during crisis situations $[26,53]$.

Sociologists call these groups of private citizens emergent organizations (e.g., [16]; [71]). In contrast to formalized organizations, emergent organizations deal with tasks that are new to them, and the relationships among the people involved are harnessed to pursue a common crisis-related goal. Emergent organizations are not always only composed of private citizens but also often include people with different backgrounds, such as those from the public sector. However, the determining factor of defining organization is not people's background but whether the organization develops new tasks and relationships and whether the organization existed before the crisis. Hence, emergent 
organizations come into being when crisis circumstances create new structures and functions [71].

Emergent groups are self-organizing and arise during crisis to meet a perceived unmet need [72] According to Kreps and Bosworth [36], organizing manifests as a sequence of four structural elements: resources, activities, tasks, and domains. Note that an organization can arise out of any combination of these elements, although some sequences are more common than others. Additionally, in emergent organizations, activities and resources normally precede, whereas tasks and domains follow [72].

Next, the relationship between SNS and these four elements are explained following the sequential order of self-organization [73].

First, human or material resources include, for instance, people with different capacities or collective technologies [36]. SNS themselves constitute material resources - collectively used technology with novel features supporting self-organization [73]. Regarding human resources, SNS help mobilize people by enabling information sharing with anyone who uses a particular SNS platform and by establishing communication channels between people who are normally separated from each other [17]. In addition, communication via SNS is not restricted to the area affected by the crisis; people unaffected by the crisis may also receive information about the situation and leverage their knowledge or resources [73].

Second, activities refer to emergent organizations' crisis-related response actions [36]. There is evidence that people can collaborate effectively online without a central control mechanism during crisis circumstances [67]. These activities, which often happen simultaneously, depend on or should at least not interfere with each other [77]. Activities can take place both online (e.g., referencing other important content) and offline (e.g., delivering food and other crisis relief efforts). SNS support both activities by enabling the exchange and consumption of almost real-time information [72]. In particular, SNS enable people to quickly receive feedback on their activities, thus allowing them to coordinate and adjust their actions. In addition, SNS help people make decisions regarding their actions by breaking time, space, and hierarchy.

Third, tasks emerge from activities and are the division of these crisis-related efforts [36]. Similar to supporting activities, SNS assist in solving tasks, such as providing warnings or keeping in touch. For instance, SNS allow people to ask for help or respond to others' immediate needs in almost real time [75].

Fourth, domains describe the overall function that directs a crisis response - that is, a crisis-related reason for a bounded unit of people to exist [36]. For instance, a pre-defined domain for a hospital is the care of victims. An emergent organization, however, has no equivalent antecedent [34]. SNS provide the opportunity to connect people with a common goal and establish relationships that would have otherwise not been established. Those groups may even have a name and may continue their work during and after the crisis event (e.g., sharing their experience or helping in another crisis). SNS support connecting the people who want to continue their crisis-related activities, building virtual communities with their own norms, membership roles, and common goals [73].

Summarizing, SNS support resource acquisition, online and offline activities, task completion, and domain building.

\section{Conceptual model and propositions}

\subsection{Conceptual model}

Building on the components explained in the theoretical background, this section introduces the conceptual research model. Using a U\&G framework, this paper's antecedents are the needs associated with risk and uncertainty reduction, trustworthy information exchange, rebuilding, and sense of community. These needs influence information seeking, information sharing, and commenting in SNS for the goal of selforganization.

Figure 1 depicts the overall research model.

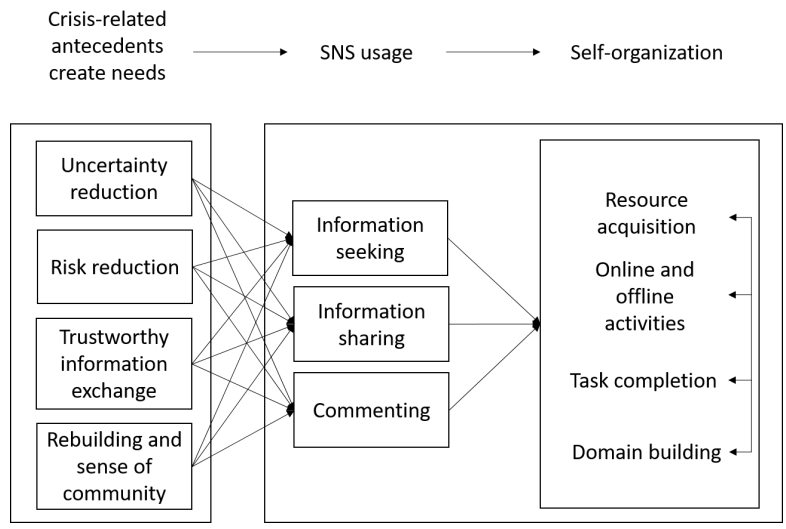

\section{Figure 1. Conceptual model}

Proposition development and dependencies between the constructs are further discussed in the following sections.

\subsection{Uncertainty reduction}

Unlike in routine situations, crisis events produce uncertainty, which means that details of the situation 
are often ambiguous, unpredictable, and/or complex, that information is inconsistent or non-existent, and that people feel insecure $[1,9]$. Uncertainty arises from limitations in individuals' ability to estimate actual events [64]. Several factors contribute to high uncertainty during crisis events, including destroyed infrastructure; a loss of sense-making; and the disruption of established patterns, structures, and routines [83]. After the terrorist attacks of 9/11, for example, people were evacuated from Lower Manhattan, and a quarantine of parts of New York City kept thousands of people away from their jobs and homes [15]. This, in turn, increased feelings of distress and uncertainty [64]. In fact, uncertainty about the cause and level of harm is one of the major consequences of a crisis situation (e.g., [31, 41, 46, 49]). In such circumstances, people engage in information seeking to acquire knowledge about the situation and observe the behavior of others to make sense of the situation [47], using their improved understanding to then reduce uncertainty [25]. Indeed, in their study of motives for information seeking at the time of the 9/11 attacks, Boyle et al. (2004) found that uncertainty reduction is one of the key reasons individuals seek information. Thus, people are likely to look to information from the media or other individuals to reduce the uncertainty generated in a crisis [37].

In addition, when uncertainties exist about, for instance, whether help will come, whether family and friends in the affected area are safe, or when the crisis might end, people's immediate need is to create a basic understanding of what happened so they can act accordingly [40]. To establish this basic understanding, information sharing among the community is necessary. SNS support this information exchange because they enable individuals to broadcast to and receive relevant information from their network in real time. This leads to the first proposition:

Proposition 1: The need to reduce uncertainty is positively related to people's SNS usage for (1a) information seeking, (1b) information sharing, and (1c) commenting in the aftermath of a crisis.

\subsection{Risk reduction}

During crises, people are likely to perceive a threat [4] because people generally worry about their safety and basic life needs [40]. In such situations, people may try to reduce the risk posed by the threat by adapting their behavior. People do not consider risk issues in isolation; rather friends, family, and/or neighbors provide reference points for validating a threat. In addition, during crisis events, information from multiple eyewitnesses may be seen as more helpful than that from traditional news sources because SNS provide more local information and more rapid updates for people who have to make decisions regarding how to act [54]. Individuals need information on how to protect themselves in the situation, how to return to normal routines, and so on. In addition, information about the consequences, duration, and scope of the harm could give clues regarding how the crisis might affect individuals personally as well as an idea of the seriousness of the crisis overall [64]. Hence, this paper argues that people will use SNS for information seeking resulting from their need for timely and local information.

Moreover, during a crisis situation, people are likely to have concerns for themselves as well as family and friends, which in turn affects their communication behavior [2]. People may not only seek information for themselves but may also assist others in receiving critical information and making the right decisions and thus upload and comment on crisisrelated information. In addition, when people experience a serious threat and try to reduce associated risk, connecting with others, asking for and receiving help, sharing information, and developing a sense of togetherness can all help relieve some of the anxiety triggered by the threat [40]. Concerns about one's own well-being and the well-being of others could increase the needs to seek, share, and comment on information via SNS, which can in turn fulfill these needs by providing a communication channel to reach many others within one's own social network in a timely manner. Thus, this paper proposes the following:

Proposition 2: The need to reduce risk is positively related to people's SNS usage for (2a) information seeking, (2b) information sharing, and (2c) commenting in the aftermath of a crisis.

\subsection{Trustworthy information exchange}

Adapting the definitions from Han et al. (2015) and Ada et al. (2016), trust is defined as the belief in the quality of the information provided by other people in SNS - that is, the belief that the information provided about the crisis event is useful, timely, and relevant. During a highly dynamic and uncertain crisis situation, trust influences the way people seek and share information [45] because they have to make decisions and take action based on the information provided [55]. Han et al. [23], for instance, found that trust in the quality of information is one of the main factors driving individuals' intentions to use emergency notification systems for receiving warning messages. Therefore, people-often finding peer-distributed content more precise and timely-may rely on SNS for 
information seeking, information sharing, and commenting in the aftermath of a crisis [54].

In addition, past research has emphasized the importance of interpersonal networks for information diffusion during crisis events. Greenberg et al. [22], for instance, discovered that half of the respondents of their study first learned about the 9/11 terrorist attacks from someone in their personal networks. Haynes et al. [24] found that people viewed friends and relatives as the most trusted sources of information about volcano eruptions. Thus, SNS that are composed of friends and friends of friends may be seen as trusted sources for information seeking as well as information exchange during crisis events [31]. Consequently, this paper proposes that heightened levels of trust in SNS positively influence the need to use SNS for browsing, information sharing, and commenting in the aftermath of a crisis. This leads to the next proposition:

Proposition 3: The need for trustworthy information exchange is positively related to people's SNS usage for (3a) information seeking, (3b) information sharing, and (3c) commenting in the aftermath of a crisis.

\subsection{Rebuilding and sense of community}

Crises have been found to create a sense of commonality and community among the affected population $[57,58,66,67]$. Generally, being a member of a group that shares the same goals can be a great source of support [3]. During crisis circumstances, in particular, finding others who care for the locale and are willing to share and exchange information as well as provide support in times of need gives new reason for forging social connections and strengthens the community feeling. These patterns of commonality help provide structure, leverage local knowledge, and rebuild the community following a crisis [67].

Moreover, according to Simon [68], people provide local information out of common concern for their community. What is more, people have reported feeling obligated to seek and exchange information as a way of relieving the concerns of those around them $[5,68]$. After a crisis, people are also interested in rebuilding their homes, businesses, and community and returning to established patterns, routines, and structures [85]. For this reason, users may utilize SNS to distribute and exchange information. Hence, this paper argues that the need to rebuild and establish a sense of community positively influences people's SNS usage for seeking, sharing, and commenting on crisis-related information, leading to this paper's next proposition:
Proposition 4: The need to rebuild and establish a sense of community is positively related to people's SNS usage for (4a) information seeking, (4b) information sharing, and (4c) commenting in the aftermath of a crisis.

\subsection{Self-organization}

Taylor et al. [76] argued that during cyclone Yasi, people had specific needs that drove their SNS usage. For instance, people used SNS to find general information about what was happening and to directly ask others for specific information. In addition, many people spent time providing general information or responding directly to questions, for instance, explaining what was happening or directing people to further information [76]. Thus, when people sense a crisis, they turn to SNS to collect or deliver timely and relevant information in order to decide how to respond.

In addition, people use SNS to make requests for help, which are then responded to by people who are offering help or practical assistance [76]. Affected people mobilize themselves and each other during crises and often turn to their communities [67]. Likewise, people in crises often note the need to contribute and help in some way, which in turn makes them feel better able to cope with the complexity of the situation [73]. Sutton et al. [73] also emphasized that crisis circumstances motivate action to provide support and assistance to others impacted by the crisis. People's SNS usage supports these activities by providing a means for communication in real time and, thus, positively influences self-organization, which leads to the final proposition:

Proposition 5: People's SNS usage for (5a) information seeking, (5b) information sharing, and (5c) commenting is positively related to selforganization in the aftermath of a crisis.

\section{Discussion, limitations, and future research}

There are some limitations to be addressed. This paper is limited by the lack of a foundational theory to form the basis for its arguments and ideas. It, therefore, focused on $U \& G$, which is a well-established theory for explaining people's SNS usage behavior outside the crisis context, research on self-organization, and on extant literature regarding people's SNS usage behavior and self-organization during crisis circumstances. Based on this literature, this paper seeks to carefully identify the antecedents of self- 
organization via SNS and associated needs during crisis situations.

While this paper includes needs that originate from a crisis event, the model ignores other needs that might be relevant for communication during crisis events (e.g., self-esteem or subjective norms). In addition, the paper does not focus on emotions, such as anxiety or fear, which may be important predictors of communication behavior in crisis situations as well. Further research could consider the role of emotions in the context of people's SNS usage for the goal of selforganization.

As this paper is conceptual, part of future research in this area should encompass empirical studies, including testing the entire research model presented herein. In order to do so, several studies will be needed to investigate the relationships among the variables in different crisis settings and in various SNS. Also, the model should be tested in different crisis phases. For example, uncertainty and risk reduction may be stronger predictors in the immediate response phase of a crisis, whereas trustworthy information exchange, rebuilding, and a sense of community might be more relevant during the recovery phase.

Furthermore, there are some challenges associated with conducting research in crisis circumstances. Crises are, by definition, infrequent and unpredictable events. People who survive such traumatic events may have difficulties sharing their perceptions or perspectives. Hence, research in this context might require carefully building unobtrusive long-term relationships with targeted people.

Finally, the model described in this paper provides a foundation for explaining the factors that influence people's SNS usage in the aftermath of a crisis and may thereby lead to a better understanding of increased SNS usage. Also, the research model highlights key issues of self-organization, yet self-organization encompasses many dimensions, some of which may be difficult to measure. Hence, the conceptual model presented in this paper should be considered a starting point for addressing the complex issues of selforganization during crisis circumstances via SNS.

\section{Conclusion}

As interest among academics and practitioners in SNS usage during crisis circumstances grows, additional research is needed to better inform theory and better assist those who manage crises. This paper's findings have several theoretical implications. The current paper contributes to the literature related to media choice, crisis informatics, and crisis communications. More specifically, this paper explores the role of specific needs that may arise during crisis circumstances and their influence on people's use of SNS for information seeking, information sharing, and commenting with the goal of self-organization during crisis events. By considering crisis situations as the context, the present paper explains why SNS usage in highly dynamic conditions is driven by other factors than in routine situations. Hence, it adds to the current theoretical explanation of SNS usage behavior by extending past research and providing a deeper theoretical understanding of the needs that drive SNS usage. Likewise, this paper provides theoretical insights by conceptualizing the mechanisms underlying people's SNS usage for self-organization in the aftermath of a crisis. Furthermore, the model proposed in this paper has some potential to measure selforganization via SNS as it covers important factors of self-organization for the crisis context as identified in the literature. Hence, the framework provides a starting point for conceptualizing self-organization via SNS during crisis situations.

The model developed also has practical implications for public authorities and crisis response organizations that must respond to inquiries and provide information on SNS during crises. As public authorities and crisis response organizations begin to realize the potential of internet-facilitated citizen coproduction of information during crisis circumstances, it is increasingly important that scholars and practitioners have an analytical framework for examining such behaviors to properly evaluate their impact and identify emerging best practices. Thus, understanding the factors that influence SNS usage for self-organization could help crisis responders connect with people more effectively.

People will continue to use SNS to receive and share information during crisis events because SNS provide novel features that meet people's needs during crises. Given the efficiency of information exchange in SNS combined with the potential to reach many people, crisis responders should proactively plan for and manage these communication channels.

\section{References}

[1] Babrow, A. S., Hines, S. C., and Kasch, C. R. 2000. Managing uncertainty in illness explanation: An application of problematic integration theory. In Explaining illness: Research, theory, and strategies. Erlbaum, Hillsdale, NJ, 47-67.

[2] Becker, S. M. 2004. Emergency communication and information issues in terrorist events involving radioactive materials. Biosecurity and Bioterrorism: Biodefense Strategy, Practice, and Science 2, 3, 1-13.

[3] Bennett, L. W. 2003. Lifestyle politics and citizen consumers: Identity, communication, and political action in 
the late modern society. In Media and political style: Essays on representation and civic, J. Corner and D. Pels, Eds. Sage, Thousand Oaks, CA, 137-150.

[4] Ben-Zur, H. and Zeidner, M. 2009. Threat to life and risktaking behaviors: A review of empirical findings and explanatory models. Personality and Social Psychology Review 13, 2, 109-128.

[5] Bird, D., Ling, M., and Haynes, K. 2012. Flooding Facebook? The use of social media during the Queensland and Victorian floods. The Australian Journal of Emergency Management 27, 1, 27-33.

[6] Blumler, J. G. 1979. The role of theory in uses and gratification research. Communication Research Reports 6, 1, 9-36.

[7] Boyed, D. M. and Ellison, N. B. 2007. Social network sites: Definition, history, and scholarship. Journal of Computer-Mediated Communication 13, 1, 210-230.

[8] Boyle, M. P., Schmierbach, M., Armstrong, C. L., McLeod, D. M., Shah, D. V., and Pan, Z. 2004. Information seeking and emotional reactions to the September 11 terrorist attacks. Journalism and Mass Communication Quarterly 81, $1,155-167$.

[9] Brashers, D. E. 2001. Communication and uncertainty management. Journal of Communication 51, 3, 477-497.

[10] Burnap, P., Williams, M. L., Sloan, L., Rana, O., Housley, W., Edwards, A., Knight, V., Procter, R., and Voss, A. 2014. Tweeting the terror: Modelling the social media reaction to the Woolwich terrorist attack. Social Network Analysis and Mining 4, 1.

[11] Campbell, S. W. and Kwak, N. 2010. Mobile communication and civic life: Linking patterns of use to civic and political engagement. Journal of Communication 60, 3, 536-555.

[12] Chaffee, S. and Metzger, M. J. 2001. The end of mass communication? Mass Communication and Society 4, 4, 365-379.

[13] Chen, R., Sharman, R., Rao, H. R., and Upadhyaya, S. J. 2008. Coordination in emergency response management. Communications of the ACM 51, 5, 66-73.

[14] Cheong, M. and Lee, V. C. S. 2011. A microbloggingbased approach to terrorism informatics: Exploration and chronicling civilian sentiment and response to terrorism events via Twitter. Information Systems Frontiers 13, 1, 4559.

[15] Dawes, S. S., Cresswell, A. M., and Cahan, B. B. 2004. Learning from crisis: Lessons in human and information infrastructure from the World Trade Center response. Social Science Computer Review 22, 1, 52-66.

[16] Drabek, T. E. and McEntire, D. A. 2003. Emergent phenomena and the sociology of disaster: Lessons, trends and opportunities from the research literature. Disaster Prevention and Management: An International Journal 12, 2, 97-112.

[17] Eismann, E., Posegga, O., and Fischbach, K. 2016. Collective behaviour, social media, and disasters: A systematic literature review. In Proceedings of the 24th European Conference on Information Systems.
[18] Fischer, D., Eismann, E., and Fischbach, K. 2016. Usage behavior of social network sites in the aftermath of terrorist attacks. In Proceedings of the 37th International Conference on Information Systems.

[19] Fischer, D., Posegga, O., and Fischbach, K. 2016. Communication barriers in crisis management: A literature review. In Proceedings of the 24th European Conference on Information Systems.

[20] Freberg, K., Saling, K., Vidoloff, K. G., and Eosco, G. 2013. Using value modeling to evaluate social media messages: The case of Hurricane Irene. Public Relations Review 39, 3, 185-192.

[21] Gil de Zúñiga, H., Jung, N., and Valenzuela, S. 2012. Social media use for news and individuals' social capital, civic engagement and political participation. Journal of Computer-Mediated Communication 17, 3, 319-336.

[22] Greenberg, B. S., Hofschire, L., and Lachlan, K. 2002. Diffusion, media use and interpersonal communication behaviors. In Communication and Terrorism. Public and Media Responses to 9/11, B. S. Greenberg, Ed. Hampton Press, Cresskill, NJ, 3-16.

[23] Han, W., Ada, S., Sharman, R., and Rao, H. R. 2015. Campus emergency notification systems: An examination of factors affecting compliance with alerts. MIS Quarterly 39, 4, 909-929.

[24] Haynes, K., Barclay, J., and Pidgeon, N. 2008. The issue of trust and its influence on risk communication during a volcanic crisis. Bulletin of Volcanology 70, 5, 605-621.

[25] Heath, R. L. and Gay, C. D. 1997. Risk communication Involvement, uncertainty, and control's effect on information scanning and monitoring by expert stakeholders. Management Communication Quarterly 10, 3, 342-372.

[26] Helsloot, I. and Ruitenberg, A. 2004. Citizen response to disasters: A survey of literature and some practical implications. Journal of Contingencies and Crisis Management 12, 3, 98-111.

[27] Heverin, T. and Zach, L. 2012. Use of microblogging for collective sense-making during violent crises: A study of three campus shootings. Journal of the American Society for Information Science and Technology 63, 1, 34-47.

[28] Huang, C.-M., Chan, E., and Hyder, A. A. 2010. Web 2.0 and internet social networking: A new tool for disaster management? Lessons from Taiwan. BMC medical informatics and decision making 10, 57.

[29] Huang, L. and Hsieh, Y. 2011. Predicting online game loyalty based on need gratification and experiential motives. Internet Research 21, 5, 581-598.

[30] Hughes, A. L. and Palen, L. 2012. The evolving role of the public information officer: An examination of social media in emergency management. Journal of Homeland Security and Emergency Management 9, 1, 1-20.

[31] Hughes, A. L. and Tapia, A. H. 2015. Social media in crisis: When professional responders meet digital volunteers. Journal of Homeland Security and Emergency Management 12, 3, 679-706.

[32] Kaewkitipong, L., Chen, C. C., and Ractham, P. 2016. A community-based approach to sharing knowledge before, 
during, and after crisis events: A case study from Thailand. Computers in Human Behavior 54, 653-666.

[33] Katz, E., Blumler, J. G., and Gurevitch, M. 1973/74. Uses and gratifications research. The Public Opinion Quarterly 37, 4 (1973/74), 509-523.

[34] Kreps, G. A. 1978. The organization of disaster response: Some fundamental theoretical issues. In Disasters. SAGE Publications Ltd, Carlifornia, 65-86.

[35] Kreps, G. A. 1984. Sociological inquiry and disaster research. Annual Review of Sociology 10, 309-330.

[36] Kreps, G. A. and Bosworth, S. L. 1993. Disaster, organizing and role enactment: A structural approach. American Journal of Sociology 99, 2, 428-463.

[37] Lachlan, K. A., Spence, P. R., and Nelson, L. D. 2010. Gender differences in negative psychological responses to crisis news: The case of the I-35W collapse. Communication Research Reports 27, 1, 38-48.

[38] Laituri, M. and Kodrich, K. 2008. On line disaster response community: People as sensors of high magnitude disasters using internet GIS. Sensors (Basel, Switzerland) 8, 5, 3037-3055.

[39] Lee, J., Agrawal, M., and Rao, H. R. 2015. Message diffusion through social network service: The case of rumor and non-rumor related tweets during Boston bombing 2013. Information System Frontiers 17, 997-1005.

[40] Leong, C. M. L., Pan, S. L., Ractham, P., and Kaewkitipong, L. 2015. ICT-enabled community empowerment in crisis response: Social media in Thailand flooding 2011. Journal of the Association for Information Systems 3, 1, 174-212.

[41] Liu, B. F., Bartz, L., and Duke, N. 2016. Communicating crisis uncertainty: A review of the knowledge gaps. Public Relations Review 42, 3, 479-487.

[42] Liu, S. B., Palen, L., Lee Hughes, A., and Vieweg, S. 2008. In search of the bigger picture: The emergent role of on-line photo sharing in times of disaster. In Proceedings of the 5th ISCRAM Conference.

[43] Lu, Y. and Yang, D. 2011. Information exchange in virtual communities under extreme disaster conditions. Decision Support Systems 50, 2, 529-538.

[44] Macias, W., Hilyard, K., and Freimuth, V. 2009. Blog functions as risk and crisis communication during Hurricane Katrina. Journal of Computer-Mediated Communication 15, $1,1-31$.

[45] Manoj, B. S. and Baker, A. H. 2007. Communication challenges in emergency response. Communications of the ACM 50, 3, 51-53.

[46] Mazer, J. P., Thompson, B., Cherry, J., Russell, M., Payne, H. J., Gail Kirby, E., and Pfohl, W. 2015. Communication in the face of a school crisis: Examining the volume and content of social media mentions during active shooter incidents. Computers in Human Behavior 53, 238 248 .

[47] McIntyre, J. J., Spence, P. R., and Lachlan, K. A. 2011. Media use and gender differences in negative psychological responses to a shooting on a university campus. Journal of School Violence 10, 3, 299-313.
[48] Mendoza, M., Poblete, B., and Castillo, C. 2010. Twitter under crisis: Can we trust what we RT? In 1st Workshop on Social Media Analytics.

[49] Moynihan, D. P. 2008. Learning under uncertainty: Networks in crisis management. Public Administration Review 68, 2, 350-365.

[50] Oh, O., Agrawal, M., and Rao, H. R. 2011. Information control and terrorism: Tracking the Mumbai terrorist attack through twitter. Information Systems Frontiers 13, 1, 33-43.

[51] Oh, O., Agrawal, M., and Rao, H. R. 2013. Community intelligence and social media services: A rumor theoretic analysis of tweets during social crisis. MIS Quarterly 37, 2, 407-426.

[52] Palen, L., Hiltz, S. R., and Liu, S. B. 2007. Online forums supporting grassroots participation in emergency preparedness and response. Communications of the ACM 50, $3,54-58$.

[53] Palen, L. and Liu, S. B. 2007. Citizen communications in crisis: Anticipating a future of ICT-supported public participation. In Proceedings of the SIGCHI Conference on Human Factors in Computing Systems, 727-736.

[54] Palen, L., Vieweg, S., Liu, S. B., and Hughes, A. L. 2009. Crisis in a networked world: Features of computermediated communication in the April 16, 2007, Virginia Tech event. Social Science Computer Review 27, 4, 467-480.

[55] Parker, D., Tapsell, S., and McCarthy, S. 2007. Enhancing the human benefits of flood warnings. Natural Hazards 43, 3, 397-414.

[56] Parker, D. J., Priest, S. J., and Tapsell, S. M. 2009. Understanding and enhancing the public's behavioural response to flood warning information. Meteorological Applications 16, 1, 103-114.

[57] Penner, L., Brannick, M., Weber, S., and Connell, P. 2005. Effects on volunteering of the September 11, 2001, attacks: An archival analysis. Journal of Applied Social Psychology 35, 7, 1333-1360.

[58] Procopio, C. H. and Procopio, S. T. 2007. Do you know what it means to miss New Orleans? Internet communication, geographic community, and social capital in crisis. Journal of Applied Communication Research 35, 1, 67-87.

[59] Renn, O. and Levine, D. 1991. Credibility and trust in risk communication. In Communicating Risks to the Public, R. E. Kasperson and P. J. M. Stallen, Eds. Springer, Netherlands, 175-218.

[60] Rotolo, T., Wilson, J., and Dietz, N. 2015. Volunteering in the United States in the aftermath of the foreclosure crisis. Nonprofit and Voluntary Sector Quarterly 44, 5, 924-944.

[61] Ruggiero, T. E. 2000. Uses and gratifications theory in the 21st century. Mass Communication \& Society 3, 1, 3-37.

[62] Seeger, M. W. 2006. Best practices in crisis communication: An expert panel process. Journal of Applied Communication Research 34, 3, 232-244.

[63] Seeger, M. W., Sellnow, T. L., and Ulmer, R. R. 2003. Communication and Organizational Crisis. Greenwood Publishing Group, Westport, CT.

[64] Seeger, M. W., Vennette, S., Ulmer, R. R., and Sellnow, T. L. 2002. Media use, information seeking, and reported 
needs in post crisis context. In Communication and Terrorism. Public and Media Responses to 9/11, B. S. Greenberg, Ed. Hampton Press, Cresskill, NJ, 53-63.

[65] Shin, D.-H. 2010. The effects of trust, security and privacy in social networking: A security-based approach to understand the pattern of adoption. Interacting with Computers 22, 5, 428-438.

[66] Shklovski, I., Burke, M., Kiesler, S., and Kraut, R. 2010. Technology adoption and use in the aftermath of Hurricane Katrina in New Orleans. American Behavioral Scientist 53, 8, 1228-1246.

[67] Shklovski, I., Palen, L., and Sutton, J. 2008. Finding community through information and communication technology during disaster events. In Proceedings of the 2008 ACM Conference on Computer Supported Cooperative Work, 127-136.

[68] Simon, T., Goldberg, A., and Adini, B. 2015. Socializing in emergencies-A review of the use of social media in emergency situations. International Journal of Information Management 35, 5, 609-619.

[69] Slovic, P. 1964. Assessment of risk taking behavior. Psychological Bulletin 61, 3, 220-233.

[70] Smith, B. G. 2010. Socially distributing public relations: Twitter, Haiti, and interactivity in social media. Public Relations Review 36, 4, 329-335.

[71] Stallings, R. A. and Quarantelli, E. L. 1985. Emergent citizen groups and emergency management. Public Administration Review 45, 93-100.

[72] Starbird, K. and Palen, L. 2011. "Voluntweeters": Selforganizing by digital volunteers in times of crisis. In Proceedings of the SIGCHI Conference on Human Factors in Computing Systems, 1071-1080.

[73] Sutton, J., Palen, L., and Shklovski, I. 2008. Backchannels on the front lines: Emergent uses of social media in the 2007 Southern California Wildfires. In ISCRAM 2008.

[74] Szymczak, H., Kucukbalaban, P., Lemanski, S., Knuth, D., and Schmidt, S. 2016. Trusting Facebook in crisis situations: The role of general use and general trust toward Facebook. Cyberpsychology, behavior and social networking 19, 1, 23-27.

[75] Tapia, A. H., Bajpai, K., Janse, J., Yen, J., and Giles, L. 2011. Seeking the trustworthy tweet: Can microblogged data fit the information needs of response and humanitarian relief organizations. In Proceedings of the 8th ISCRAM 2011, 110.

[76] Taylor, M., Wells, G., Howell, G., and Raphael, B. 2012. The role of social media as psychological first aid as a support to community resilience building. A Facebook study from 'Cyclone Yasi Update'. The Australian Journal of Emergency Management 27, 1, 20-26.

[77] Tim, Y., Pan, S. L., Ractham, P., and Kaewkitipong, L. 2016. Digitally enabled disaster response. The emergence of social media as boundary objects in a flooding disaster. Information Systems Journal 27, 2, 197-232.

[78] Veil, S. R., Buehner, T., and Palenchar, M. J. 2011. A work-in-process literature review: Incorporating social media in risk and crisis communication. Journal of Contingencies and Crisis Management 19, 2, 110-122.

[79] Vieweg, S., Hughes, A. L., Starbird, K., and Palen, L. 2010. Microblogging during two natural hazards events: What Twitter may contribute to situational awareness. In Proceedings of the SIGCHI Conference on Human Factors in Computing Systems Pages, 1079-1088.

[80] Wang, X. 2014. How do people participate in social network sites after crises? A self-determination perspective. Social Science Computer Review 32, 5, 662-677.

[81] Wang, X. 2016. People's motivation to participate in social network sites, subsequent behaviours, and situation self-awareness following a crisis: Evidence from the MH370 flight incident. Australasian Journal of Emergency Management 20, 1-21.

[82] Wei, R. 2008. Motivations for using the mobile phone for mass communications and entertainment. Telematics and Informatics 25, 1, 36-46.

[83] Weick, K. E. 1988. Enacted sensemaking in crisis situations. Journal of Management Studies 25, 4, 305-317.

[84] Whittaker, J., McLennan, B., and Handmer, J. 2015. A review of informal volunteerism in emergencies and disasters: Definition, opportunities and challenges. International Journal of Disaster Risk Reduction 13, 358368.

[85] Wolensky, R. P. 1979. Toward a broader conceptualization of volunteerism in disaster. Journal of Voluntary Action Research, 33-42.

[86] Xu, C., Ryan, S., Prybutok, V., and Wen, C. 2012. It is not for fun: An examination of social network site usage. Information \& Management 49, 5, 210-217.

[87] Yates, D. and Paquette, S. 2011. Emergency knowledge management and social media technologies: A case study of the 2010 Haitian earthquake. International Journal of Information Management 31, 1, 6-13.

[88] Zhou, Y., Yang, L., van de Walle, B., and Han, C. 2013. Classification of microblogs for support emergency responses: Case study Yushu earthquake in China. In 46th Hawaii International Conference on System Sciences (HICSS), 1553-1562. 